\section{The Trouble with Testosterone}

\author{
and Other Essays on the Biology \\ of the Human Predicament
}

\section{by Robert M. Sapolsky \\ Simon \& Schuster Inc.}

New York, New York, \$23.00, hardcover ISBN: 0-684-83409-X, 1997

\section{Reviewed by Laura P. BonetTa Associate Editor, Nature Medicine}

Ever wonder why in times of stress you might find it reassuring to count the number of steps going up a flight of stairs? Why drivers slow down to watch the scene of an accident? Why some people, especially young ones, seek novelty and excitement while others do not? Robert M. Sapolsky is fascinated by questions like these, and pursues their scientific explanation drawing from modern psychiatry, neurobiology, evolutionary biology and animal behavior.

Although the title of his latest book, The Trouble with Testosterone, suggests that it will enlighten us as to the downside of being male, the book is in fact a collection of essays covering a broad range of subjects (including testosterone). The common denominator is that they all deal with some aspect of behavior. A few recurring themes and concepts run through the book, and the essays can be loosely grouped accordingly.

One group deals primarily with "abnormal" human behavior and mental illnesses. The book opens with a fascinating tour of neuropsychiatric oddities, including Tourettes' syndrome ("hiccups of the id"), obsessive-compulsive disorder and schizophrenia. Sapolsky describes what is known of the underlying causes for these diseases and the insights they provide into our more benign quirks and everyday peculiarities. For instance, there is evidence that a certain genetic makeup predisposes to schizophrenia. Would a milder version of this makeup predispose one to place a strong faith in magical ideas? The message that emerges from these stories is that there is continuity between the workings of our personality traits and the more extreme versions that might qualify as disease. He writes, "Being healthy, it has been said, really consists of having the same disease as everyone else."
Aside from psychiatric disorders, a number of essays are devoted to the biological and endocrinological underpinnings of less extraneous behaviors. "The Trouble with Testosterone" - one of the more engaging essays in the book - deals with the link between testosterone levels and aggressive behavior. It covers the evolution of scientific evidence, initially pointing to testosterone as the sole culprit, to the currently held view that testosterone does not cause aggression, but rather exaggerates the aggression that is already there. So we find out what the trouble with testosterone really is: The tendency of people to reduce

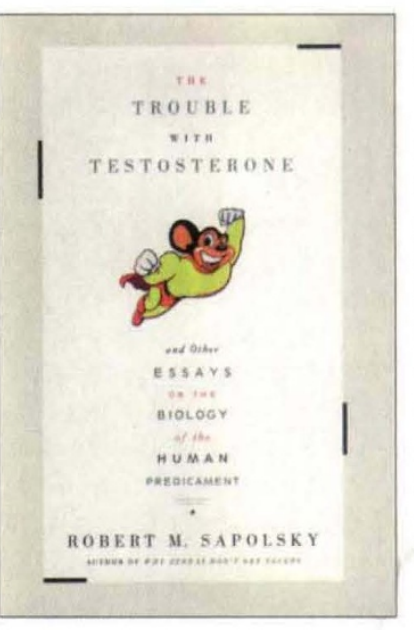
on this finding, Sapolsky uses the example to discuss the type of questions that it raises. He does not say that this kind of research should not be carried out, but rather warns that we should think about possible problems that might arise from it.

A few of the essays did not seem to fit into any of the above categories and departed from scientific arguments. As far as I could tell, they were just things that the author wanted to get off his chest. In one essay, he talks about Ted Kaczynsky (the alleged Unabomber) and why one should not condone his actions; in something as complex as behavior to a single gene or hormone or neurotransmitter or part of the brain, as the cause or explanation of everything (what Sapolsky calls "physics' envy").

When the author is not working in his laboratory, studying neurons and stress hormones, he spends time in East Africa, following troops of wild baboons - no doubt the inspiration for his essays dealing with animal behavior. These I found the most entertaining. The general picture that emerges from these stories is that humans share many behaviors, stresses and excitements with baboons. "Primate Peekaboo" describes the voyeurism practiced by most baboons, apparently for the sheer pleasure of it, and "The Young and the Reckless" considers the behavior of the young novelty- or thrill-seeker. Young baboons must leave their group and set out on their own to avoid the problem of inbreeding. Is our own itch to leave home a testament to our primate legacy? Sapolsky's view is clearly that we humans are just another primate species, but with a "more fancy set of thumbs".

Throughout the book, we are reminded of the political and social implications of this research. The title of the essay "How Big is Yours" refers to the discovery by the neurobiologist Simon Levay demonstrating that the size of the third interstitial nucleus in the brain of homosexual men is smaller than that in heterosexual men. Although, the scientific jury is still out another, "The Dangers of Fallen Soufflés in the Developing World", he shares his thoughts as to why partial Westernization is causing havoc in Africa. These pieces are not compelling, and what could have been said in a couple of sentences ends up filling up far too many pages.

By and large, the book makes for very interesting and enjoyable reading. Those who have read Sapolsky's earlier books will be familiar with his casual and accessible style of writing. Although the ideas he presents are complex and often provocative, the facts are kept relatively simple. Throughout, the science is interspersed with personal anecdotes and humorous asides. (When illustrating our tendency to be voyeuristic he admits to having followed intently every detail of the O.J. Simpson trial).

Sapolsky clearly loves science and imparts his enthusiasm to the reader. He is aware of the potential dangers and pitfalls, but believes that when science is done right society as a whole will benefit and experience growth. At the end of the book, he reassures the public: Science will not one day explain everything about human nature so as to dissipate our sense of self and individuality. He says that will never happen, as for every question that is answered, there are many more that are generated. "The purpose of science is not to cure us of our sense of mystery and wonder, but to constantly reinvent and reinvigorate it". 